\title{
BEHAVIOR OF BEAM-TO-COLUMN CONNECTIONS WITH ANGLES. PART 2- NUMERICAL ANALYSIS
}

\author{
M. Ghindea ${ }^{\text {a }}$, A. Cătărig ${ }^{\text {a, } * \text {, R. Ballok }}{ }^{\text {a }}$ \\ ${ }^{a}$ Technical University of Cluj-Napoca, Faculty of Civil Engineering, 28 Memorandumului Street, 400114 , Cluj-Napoca, Romania
} Received: 16.02.2016 / Accepted: 03.03.2016 / Revised: 30.02.2016 / Available online: 31.05.2016

DOI: $10.1515 /$ jaes-2016-0004

KEY WORDS: experimental investigation, beam-to-column joint, semi-rigid connection, bolted connection, angle cleat

\begin{abstract}
:
Based on the results of experimental tests, presented in the first part of this paper, Part 1- Experimental Investigations (Ghindea M., Catarig A., Ballok R.) advanced numerical simulations were performed using FEM based software Abaqus. The recently arise of high speed computers and advanced FEM software packages allow to create and solve extensively detailed 3D models. The aim of this second part of the paper is to develop accurate FEM models for better approach of the studied beam-to-column connections. The paper presents the designed numerical models and the results for four bolted beam-to-column connections using top-and-seat and/or web angle cleats, in different configurations. The objective of this paper is to achieve functional numerical models which, by faithfully running, reproduce the experimental results. Thus, calibrating the numerical results with the experimental ones it can be perform then parametric studies, achieving reliable results for similar configurations of joints. The results obtained after numerical simulations were compared with experimental data. The behavior moment-rotation curve and the deformation process of the experimental captured specimens were virtually reproduced with minimum deviation.
\end{abstract}

\section{INTRODUCTION}

Problems, including complex loads and geometrical configurations with properties for materials with nonlinear behavior, are in general impossible to be solved through analytical methods. In these conditions, in order to obtain a satisfactory solution, it is necessary to use some numerical methods (Catarig, Mathe, Chira, Popa, 2010), (Mathe, Catarig, Moldovan, 2015). Numerical analyses with finite elements are a suitable and effective way to simulate experimental tests.

These analyses are relatively cheap compared to experimental testing, both financially and in terms of time (Pirmoz, 2009), (Calado, 2000), (Bo Yang, 2012). However, the existence of some experimental data is considered vital in the calibration process of the model with finite elements. This technique makes it possible to investigate a whole series of parameters using the calibrated model (Davor Skejic, 2013). The method of finite elements has a widespread use in the structures analysis (Gîlia, 2012), (Schrauben, 1999), (Citipitioglu, 2002), (X.G. Lin, 2008). Annex C from EN1993-1-5 provides guidance regarding use of the finite elements method for the ultimate limit state, serviceable limit state or fatigue verifications of the plate structures. Modelling with MEF can be done for the whole structure or for a substructure. Validation of a FEM model by comparing with experimental results enables further studies in order to find out a simplified calculation method (Bâlc, 2012).

The purpose of this paper is to describe the steps that were followed to obtain an advanced numerical model to simulate the behavior of beam-to-column connections made with angles, experimentally studied. The model was calibrated using the experimental data presented in the first part of this paper (Ghindea, Catarig, Ballok, 2015).

For numerical modelling it was used the program with finite elements ABAQUS/CAE 6.11 (Abaqus, 2011) a software able to incorporate in the developed models the detailed joint configuration. Experimental tests were conducted in monotonous static state, which causes, at first glance, the use of FEM analyses as default ,solver”. Due to the large number of finite elements present within each analysis and because of many conditions of boundaries and interactions present in the proposed model, for the performed simulations it has been

\footnotetext{
* Corresponding author, e-mail: alex.catarig@mecon.utcluj.ro
} 
chosen the ABAQUS/Explicit (Abaqus, 2011) solver. This package is able to effectively incorporate different contact discontinuities, present throughout the analysis. This thing is done through a default algorithm without selectively specify the contact areas in a preliminary stage of the analysis. The explicit package provides the capability to simulate $3 \mathrm{D}$ models, both involving contact and large deformations of the component parts.

\section{NUMERICAL MODELLING}

For the modeling of beam-to-column connections were taken into account the modeling assumptions specific to the GMNA analysis (The geometric nonlinear analysis with material nonlinearity of a perfect structure), because this configuration of the specimen, which is composed of short linear elements, the imperfections have an insignificant contribution.

Static analyses were performed with the ABAQUS/Explicit package. The explicit procedure was originally developed to model phenomena with high speeds of development and/or impact, and so it included dynamic effects throughout the simulation. They have an emphasized effect in case of simulate phenomena with short development time. The static analyses worked out with ABAQUS/Explicit are considered quasi-static in the literature, given the fact that the dynamic effects do not cease during analysis, but are only reduced as intensity and are considered negligible. Reducing the length of the simulated process may have dominant effect in the general state of equilibrium. It can evolve from a state of static equilibrium to a dynamic equilibrium. The main condition for an analysis to be quasi-static is that the global ratio between kinetic energy of the model and the energy from the deformations of the elements included in the model to be negligible (Abaqus, 2011).

For the calibration of the finite element model it was necessary to use some characteristic material curves for the parts of the node. The steel of the elements is the same as the one used for the reference experiment, namely S275. After obtaining identical results for the reference experiment, in this stage of research, for the numerical models it has been used the curve of the steel obtained on material specimens S275 by the authors in Spain, from the Technical University La Corunia (Reynosa, 2014), (Reynosa, 2008). This curve is shown in Figure 1.

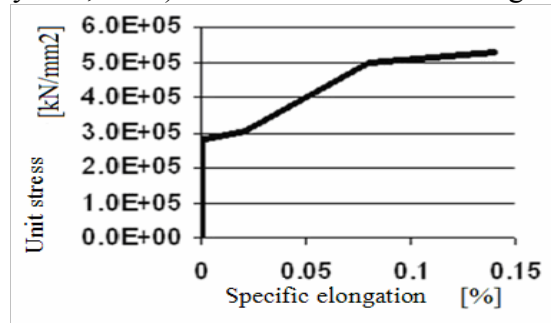

Figure 1. Characteristic curve of the steel S275 (Reynosa, 2014)

The elastic modulus is $210000 \mathrm{~N} / \mathrm{mm}^{2}$. For the Poisson coefficient it has been chosen as $v=0.3$ and the material density is the usual one for the steel, $7850 \mathrm{~kg} / \mathrm{m}^{3}$. The bolts belong to group 10.9 and their material has been defined with the yield strength $f_{\mathrm{y}}=900 \mathrm{~N} / \mathrm{mm}^{2}$, respectively the ultimate strength $f_{u}=1000 \mathrm{~N} / \mathrm{mm}^{2}$. The modelling does not include pre- tension of bolts, and thus, in order to avoid slips, the holes diameter is equal with that of the bolts.

The pieces were connected using the interaction „General Contact" type with a law of interaction in two directions (normal/tangential). This law of contact is available in the explicit library in Abaqus, and can be relatively easy defined. Therefore, the contact is defined having two key properties: on the normal direction between surfaces it was chosen a law of behavior „Hard contact” type, and on the tangential direction it was chosen a low of contact with friction, with the commonly coefficient used in case of steel surfaces as $\mu=0.3$. Thus, it is taken into account the friction assumption between two steel surfaces, namely the fact that on the normal direction it is necessary and compulsory the condition that a metal surface does not enter into the other one.

On each beam end it has been placed a reference point to which it was blocked its degrees of translational freedom on vertical and lateral directions, in order to obtain theoretical joints. Also, in the upper part of the column it has been placed another reference point where the displacement was applied.

„Tie” joints were used several times. This type of connection suppresses independent translations and rotations between parts and was used in modeling the connections between nut and bolt.

The finite elements used for „Solid" type pieces (column, beams, bolts, nuts, angles) were hexagonal type with 8 nodes and reduced integration (C3D8R). The type of the element used C3D8R is shown in Figure 2.

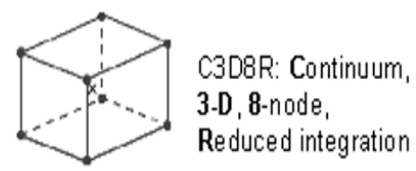

Figure 2. The type of the finite element used (Abaqus, 2011)

All items of the meshing obtained within the parts assembly have direct contact. The maximum size of the discretization mesh has been chosen after the optimization process: $12 \mathrm{~mm}$ for steel profiles, respectively $4 \mathrm{~mm}$ for bolts and the bolt holes. The angles have a discretization at $8 \mathrm{~mm}$ because between them take place large deformations. The components of the assembly had a structured discretization network, the only exception being around, where it was necessary a free discretization, using cutting plans.

The numerical models for those 4 experimental tested specimens are made by small geometric modifications of the basic model. Thus, the modelling principles and solutions are not changes. Models made for those 4 configurations of doublesided connections are shown in Figure 3.

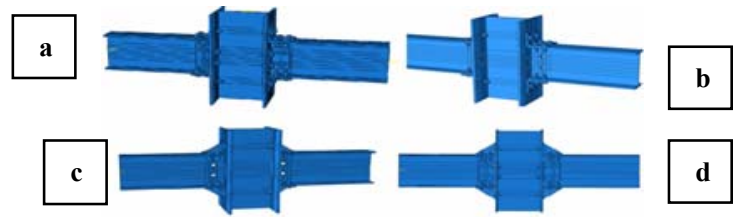

Figure 3. 3D Models of tested specimens: a) TSW-10, b) TS-10, b) TSS-10, d) TSWS-10 


\section{NUMERICAL RESULTS}

The numerical results are compared with the experimental ones, both by overlapping the characteristic moment-rotation curves and visual examination of strains and phenomena compared with those captured during laboratory experiments. The beamto-column moment, respectively the rotation, were assessed in compliance with Figure 4.

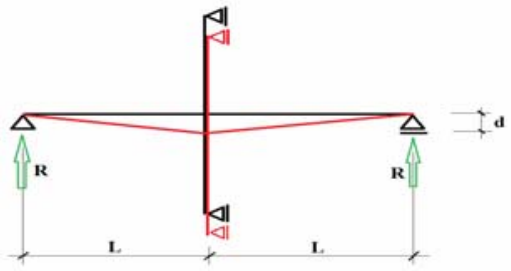

Figure 4. Static diagram of the nodes considered in the numerical models

Thus, the moment taken by the connections was calculated by considering the reaction , $R$ " achieved and the strength arm , $L "$. The rotation was assessed by rotation angle calculation, using the following parameters: $d$-displacement, $L$ - beam length. The angle assessed by relation $\operatorname{atg}(d / L)$, represents exclusively the joint rotation at the moment arising from reaction $R$, because according to the static system of the numerical model and the experimental one, the column slides vertically, without an additional rotation. The numerical simulations allow color viewing of tensions state. The specimen deformation for those 4 choices considered are similar, the main differences are observed by comparing the behavior curves.

\subsection{TSW-10 test}

Figure 5 presents the distribution of tensions „Von Mises” for the configuration of specimen TSW-10. The joint area is a sensitive one because of discontinuities causing stresses concentration and high stresses.

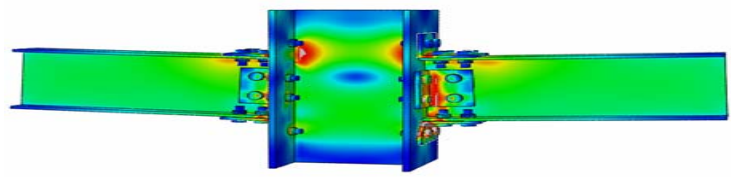

Figure 5. Distribution of Von Mises tensions and specimen strain

The angle from the lower chord (tension zone) is deformed as in case of the laboratory experiment (Figure 6). The numerical simulation shows in colors the areas with high concentrations of tensions.
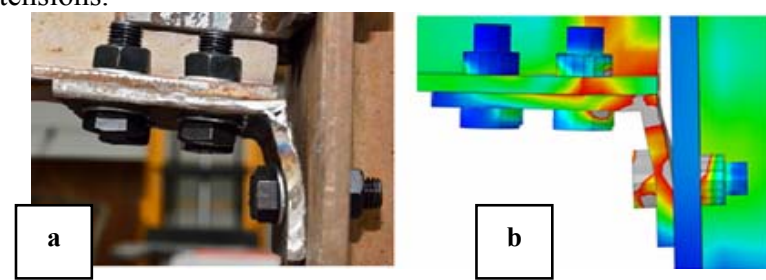

Figure 6. Deformation of the angle from the lower chord: experiment and Abaqus
The characteristic moment-rotation curve experimentally and numerical obtained for specimen TSW-10 is shown in Figure 7.

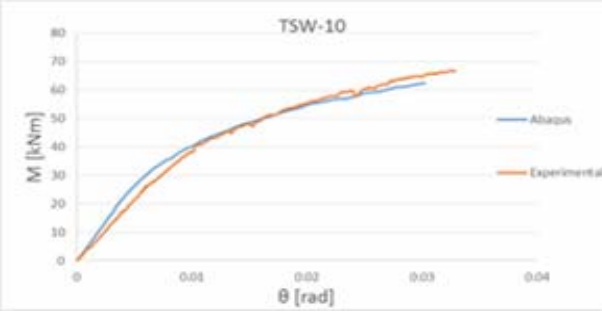

Figure 7. Characteristic moment-rotation curves

\subsection{TS-10 test}

Figure 8 shows the strain and tension state for specimen TS- 10 .

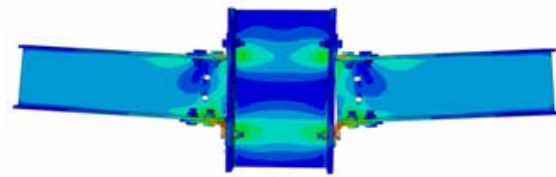

Figure 8. Deformation of the angle from the lower chord (tension zone): experiment and Abaqus

Figure 9 highlights the lower angle deformation. It is deformed as in case of unstiffened angles connections: by bending the angle wing which is in contact with the column face. In the absence of web angles the shear is taken on the column face, at the top-and-seat angles level, by bolts shearing and pressure on the columns and angles bolt holes.
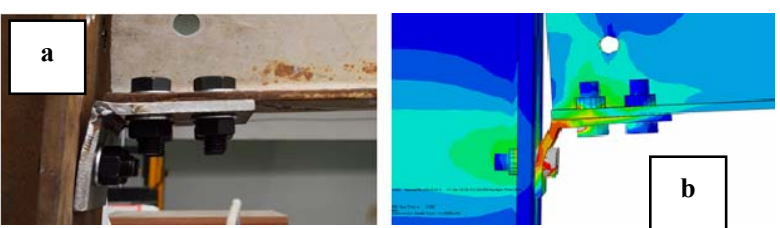

Figure 9. Deformation of the angle from the lower chord: experiment and Abaqus

Figure 10 shows comparatively the strains produced at the angles level by laboratory test and numerical simulation. Figure 10.a was obtained after disassembling of the tested specimen, as well as the left image (Figure 10.b) was obtained by hiding the components except the angles. In case of the view in Abaqus (Figure 10.b), the stress concentration in the angles is also highlighted. It can be seen the angles deformations depending on their placement in the joint (compressed angle upper area, stretched angle - lower area).

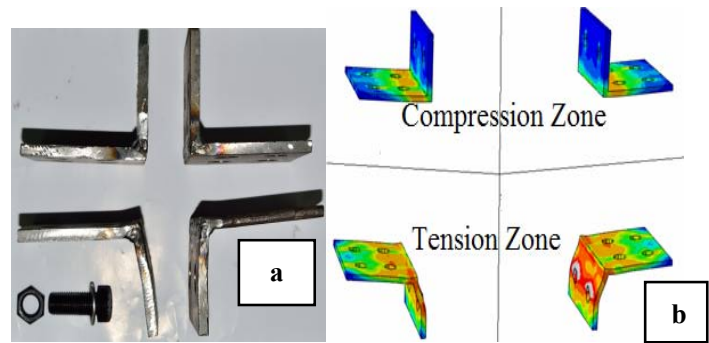

Figure 10. Deformation of the angle from the stretched top-andseat: experiment and Abaqus 
The characteristic moment-rotation curve experimentally and numerical obtained for specimen TS-10 is shown in Figure 11. In this case, the behavior obtained by numerical simulation slightly overestimates the rotation stiffness of the joint, the differences being acceptable.

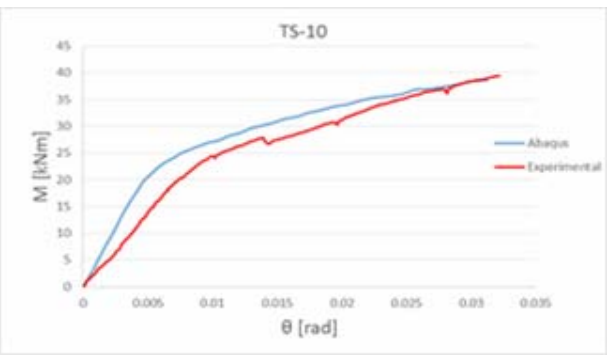

Figure 11. Characteristic moment-rotation curve

\subsection{TSS-10 test}

The numerical result obtained for specimen TSS-10 shows a stiffer behavior with small deformations of the angles (Figure 12).

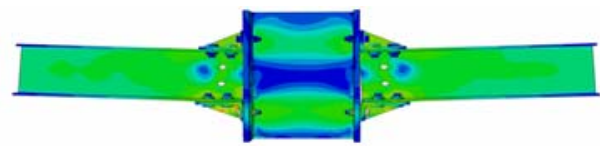

Figure 12. Distribution of Von Mises tensions and specimen strain

Input of stiffness significantly reduce the angle flexibility, and thus, results a connection with higher stiffness and resistance. Figure 13 shows identical deformed shape for stiffened angle, obtained experimentally and numerically.
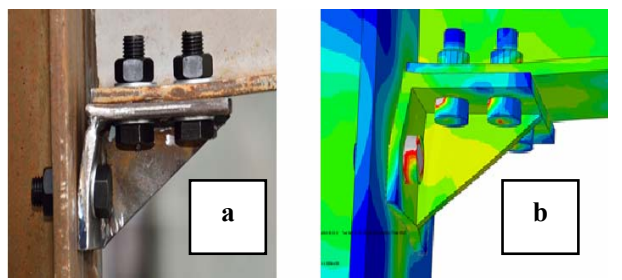

Figure 13. Deformation of the angle from the stretched top-andseat: experiment and Abaqus

Remove of beams and columns from the output data of the result allows hidden areas viewing. In Figure 14 are shown comparatively the deformations produced at the angles level by laboratory testing and numerical simulation (same comparison as in case of Figure 10).

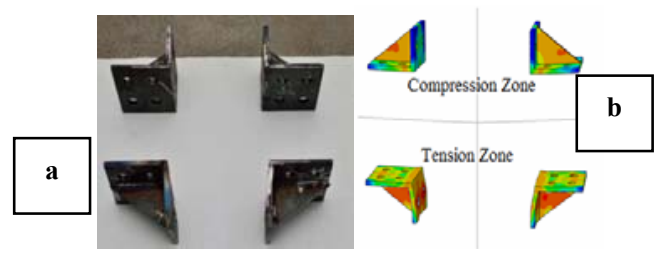

Figure 14. Deformation of the angle from the stretched top-andseat: experiment and Abaqus
In Figure 15 are graphically shown the curve obtained by numerical analysis compared with the curve experimentally obtained. In case of specimen TSS-10 the numerical model provides a very good simulation of the experimental test, as regards the original stiffness and flexible behavior at high moment values.

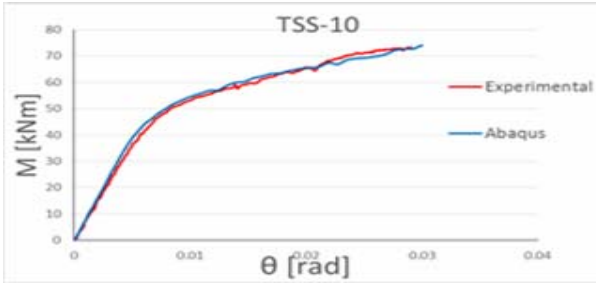

Figure 15. Characteristic moment-rotation curves

\subsection{TSWS-10 test}

Figure 16 shows the tensions state and strain numerically obtained for specimen TSWS-10.

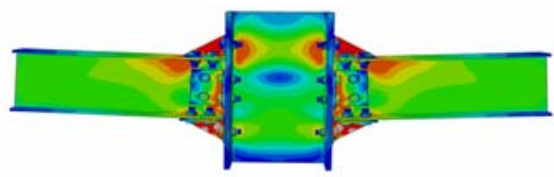

Figure 16. Distribution of Von Mises tensions and specimen strain

At high levels of loading it is seen the deformation of the topand-seat, adjacent to the connection, a phenomenon noticed also in case of the laboratory test. Both experimental and numerical captures are presented in Figure 17.

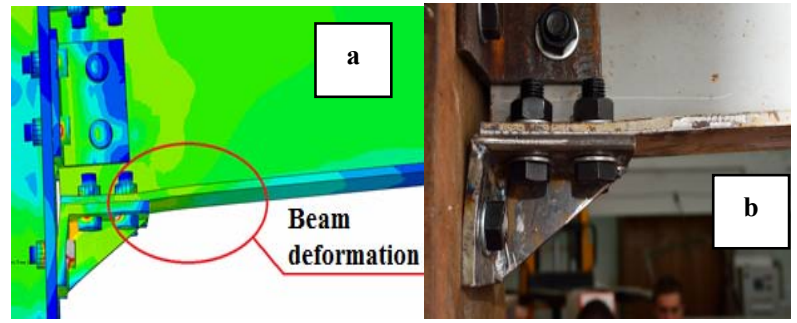

Figure 17. Deformation of angle from lower chord of the beam (tension zone): experiment and Abaqus

Figure 18 shows the strains and concentrations of tensions in top-and-seat and web angles.

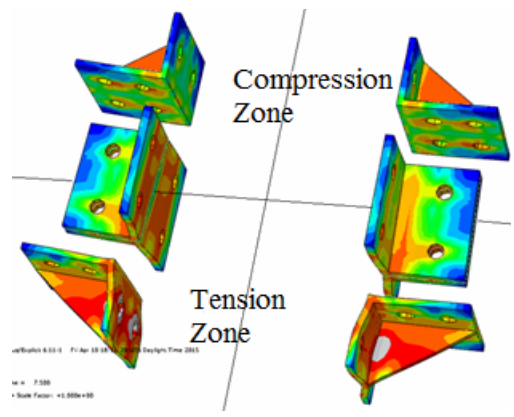

Figure 18. View of tensions in angles from TSWS-10 connection 
The behavior of moment-rotation curves experimentally and numerically obtained is graphically shown in Figure 19. The $93 \mathrm{kNm}$ moment value, recorded as maximum value in case of TSWS-10 connection, exceeds the $89 \mathrm{kNm}$ beam moment value (IPE240 made of steel S275), which explains the cause of beam deformation, noticed experimentally and numerically.

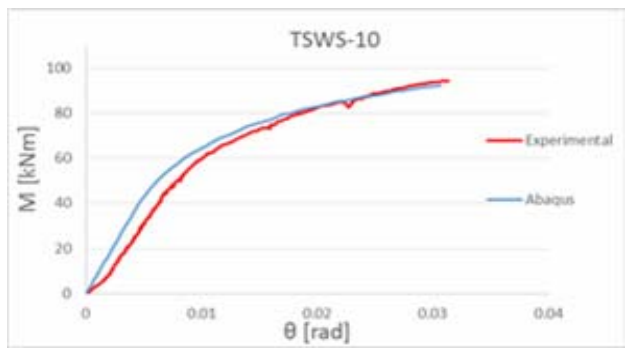

Figure 19. Characteristic moment-rotation curves

\section{CONCLUSIONS}

The paper presented the models and numerical results calibrated with laboratory experiments for four different configurations of beam-to-column connections. They confirm for all four variants of joint the fidelity of the numerical model. It is noticed a good correspondence of stiffness and bearing capacity for the bending moment.

The calibrated numerical model offers a better understanding of the behavior of studied joints, reaching a higher level of results comparatively with those presented in the previous part of this paper (Ghindea, Catarig, Ballok, 2015). Compared to the experimental data, where a reduced number of parameters were monitored, the numerical results allow monitoring of the tensions and displacement of each point of the discretization network.

Most of the joints are partially resistant except for TSWS- 10 connection which is totally resistant. In its case, the $93 \mathrm{kNm}$ moment value, recorded as maximum value in case of TSWS10 connection, exceeds the $89 \mathrm{kNm}$ beam moment capacity value (IPE240 made of steel S275), leading to deformation in the beam.

The connections behavior studied by the authors can be introduced in framed steel structures with various spans and column heights, keeping obviously the same beam and column sections. Such further studies on an entire frame will give more practical conclusions, regarding the behavior of the frame at limit states.

\section{REFERENCES}

Catarig Al., Mathe Aliz, Chira N., Popa Anca, (2010). Steel Structures with Semi-Rigid Connections. Annals of University of Oradea, Construction and Hidro-Utility Instalation. Vol. XIII-2, pag.21-32.

Mathe Aliz, Catarig A1., Moldovan Ilinca, (2015). Statics and Kinematics of Semirigid Steel Frames under Seismic Action. Journal of Applied Engineering Sciences, Volume 5(18), Issue 2/2015, pag.59-64.
Pirmoz, A., (2009). Moment-rotation behavior of bolted topseat angle connections. Journal of Constructional Steel Research 65, pp.973-984.

Bâlc, Roxana, (2012). Finite element analysis of beam to column end plate bolted connection. Acta Technica Napocensis: Civil Engineering \& Architecture, Vol.55, No.1, pp.24-29.

Bo Yang, Kang Hai Tan, (2012). Numerical analyses of steel beam-column joints subjected to catenary action - Journal of Constructional Steel Research 70 1-1

Citipitioglu, A.M., Haj-Ali, R.M., White, D.W. (2002). Refined $3 D$ Finite Element Modelling of Partially-Restrained Connections Including Slip. Journal of Constructional Steel Research, 58(5-8), pp. 995-1013.

Davor Skejic, D.D., (2013). Finite Element Modelling of the Flange Cleats. Design, Fabrication and Economy of Metal Structures. Proceedings of International Conference, Miskolc, Hungary, SPRINGER.

Gîlia, L., (2012). Structural performance study of cold-formed girders composed of $C$ cross-section flanges and corrugated web. Cluj-Napoca Phd. Thesis, Technical University of ClujNapoca \& "Politehnica" University of Timisoara.

Reynosa, J. M., (2008). Nonlinear elastic-plastic 3d finite element modelling of top and seat angle connections with double web angle. En Eurosteel 2008: 5 European Conference on Steel and Composite Structures, Volume A, Graz, Austria, pp.501-506.

Reynosa, J. M., Loureiro, A., (2014). Experimental and numerical study of angle connections assembled with European profiles. Informes de la Construcción, Vol. 66.

Calado, L.E.M., (2000). 1. Experimental behavior of steel beam-to-column joints. Fully welded vs. bolted connections. 12WCEE2000.

Ghindea, M., Cătărig, A., Ballok, R., (2015). Behavior of Bolted Beam-to-Column Connections Using Angles. Part 1 Experimental Investigations. Journal of Applied Science, 2015, pp.21-28.

Lin, X.G., (2008). Prediction of initial stiffness of semi-rigid steel beam-to-column with bolts and angles. The 14th World Conference on Earthquake Engineering, Beijing, China.

Abaqus, (2011). Analysis User's Manual, Dassault Systèmes Simulia Corp., Providence, RI, USA.

Abaqus, (2011). Benchmarks Manual, Dassault Systèmes Simulia Corp., Providence, RI, USA.

Abaqus, (2011). User's Manual, Dassault Systèmes Simulia Corp., Providence, RI, USA. 
SR EN 1993, (2008). Eurocod 3: Proiectarea structurilor de oțel. Partea 1-5: Elemente structurale din plăci plane solicitate in planul lor, ASRO.

Schrauben, C., (1999). Behavior of Full-Scale Bolted Beam to Column T-stub and Clip Angle Connections under Cyclic Loading. MS Thesis, Georgia Institute of Technology. 